\title{
Erratum to: 28 Days Later: Twitter Hashtags as "Just in Time" Teacher Professional Development
}

\author{
Spencer P. Greenhalgh ${ }^{1}$ • Matthew J. Koehler ${ }^{2}$
}

Published online: 10 March 2017

(C) Association for Educational Communications \& Technology 2017

Erratum to: TechTrends (2016)

DOI 10.1007/s11528-016-0142-4

The original article contains an error in Fig. 5; the axis labels for Fig. 5 of the manuscript should be reversed. Below is the corrected version of Fig. 5.

The online version of the original article can be found at http://dx.doi. org/10.1007/s11528-016-0142-4

Spencer P. Greenhalgh

greenha6@msu.edu

Matthew J. Koehler

mkoehler@msu.edu

1 Department of Counseling, Educational Psychology and Special Education, Michigan State University, 447 Erickson Hall, 620 Farm Lane, East Lansing, MI 48824, USA

2 Department of Counseling, Educational Psychology and Special Education, Michigan State University, 509E Erickson Hall, 620 Farm Lane, East Lansing, MI 48824, USA 


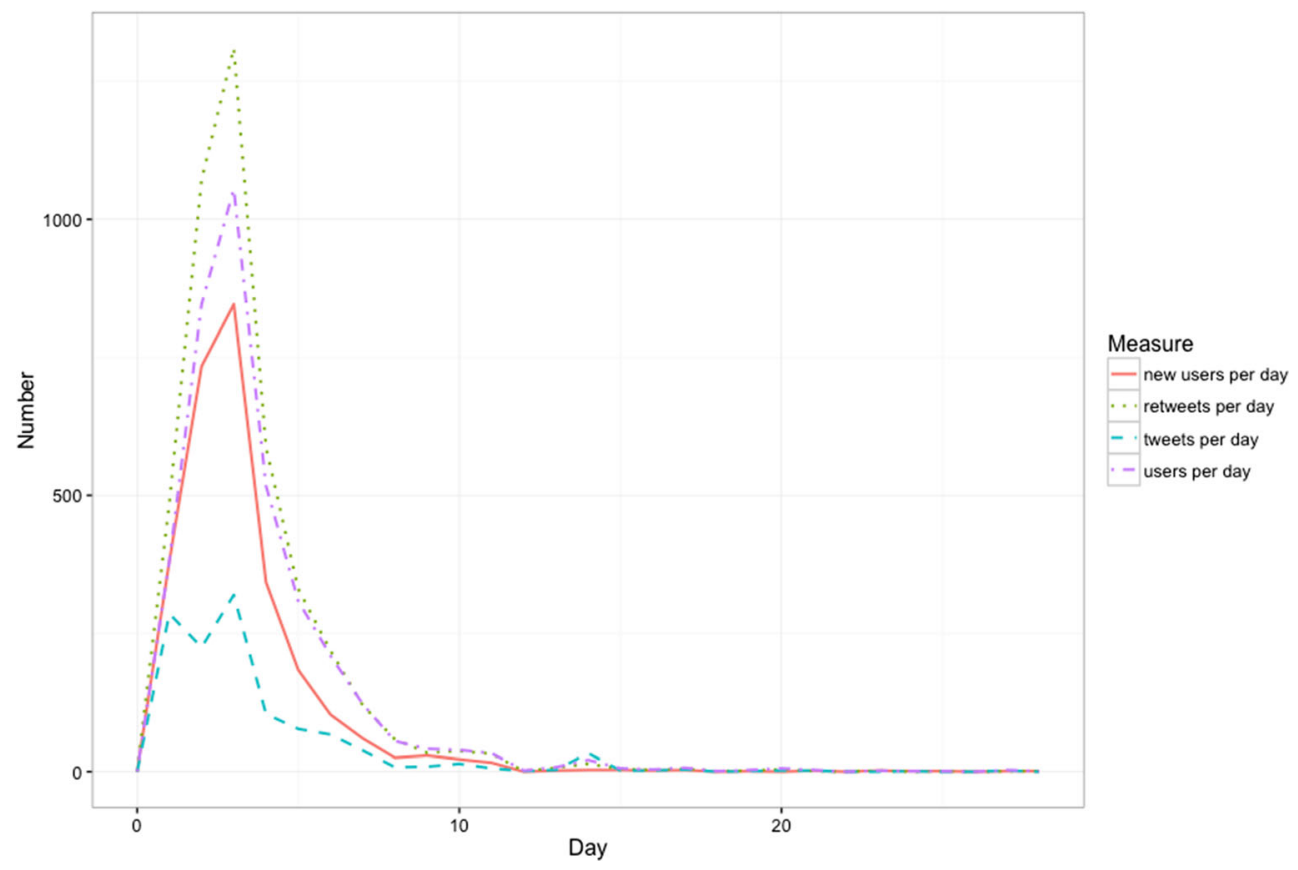

